\title{
Functional results and quality of life after transanal total mesorectal excision
}

\author{
Paola De Nardi \\ Gastrointestinal Surgery, San Raffaele Scientific Institute, Milan 20132, Italy.
}

Correspondence to: Dr. Paola De Nardi, San Raffaele Scientific Institute, Via Olgettina 60, Milan 20132, Italy.

E-mail: denardi.paola@hsr.it

How to cite this article: De Nardi P. Functional results and quality of life after transanal total mesorectal excision. Mini-invasive Surg 2018;2:20. http://dx.doi.org/10.20517/2574-1225.2018.30

Received: 28 May 2018 First Decision: 14 Jun 2018 Revised: 16 Jul 2018 Accepted: 17 Jul 2018 Published: 24 Jul 2018

Science Editor: Gordon N. Buchanan Copy Editor: Jun-Yao Li Production Editor: Huan-Liang Wu

\begin{abstract}
This is a narrative review on ano-rectal, sexual, urinary, and quality of life outcomes after transanal total mesorectal excision (TME). Little is known on this topic as only a few studies are currently available in the literature. According to these, it appears that the functional results and quality of life are not substantially impaired compared with standard TME. However more data are needed to precisely assess the outcomes of this technique.
\end{abstract}

Keywords: Rectal cancer, transanal total mesorectal excision, functional results, quality of life

\section{INTRODUCTION}

Rectal resection with total mesorectal excision (TME) is considered the standard treatment for cancer located in the mid and low rectum, as it provides removal of the primary tumor together with the mesorectal lymph nodes ${ }^{[1]}$. However, TME for low rectal cancers, whether performed via an open or conventional laparoscopic approach, is technically demanding, particularly in patients with unfavourable features such as obese male patients, with a narrow pelvis or bulky tumor, where obtaining adequate resection margins can be challenging. The transanal total mesorectal excision (taTME) technique has been recently introduced to facilitate distal mobilization of the rectum and has raised great interest worldwide since it may overcome some of the limitations encountered in abdominal $\mathrm{TME}^{[2]}$.

Compared to standard laparoscopic TME, taTME has potential advantages: a superior quality of the specimen with better preservation of mesorectal integrity ${ }^{[3,4]}$, a better anastomotic technique ${ }^{[5,6]}$, no need for an abdominal incision for specimen extraction, reduced incidence of wound problems ${ }^{[7]}$, less conversions to

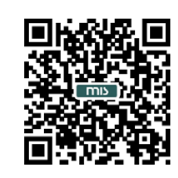


open surgery, more sphincter-saving procedures and no impairment of oncological outcomes ${ }^{[8-10]}$. Another benefit is that the visualization of the surgical plane is improved in the more difficult part of the operation, namely the mid- and low rectum, thus allowing more accurate dissection. Potentially, this could enhance the identification of the pelvic autonomic nerves and their sparing, thus better preserving sexual and voiding functions. Chouillard et al. ${ }^{[11]}$ compared intraoperative visualization of the neurovascular bundles of Walsh in patients undergoing standard laparoscopic TME or taTME. Bilateral visualization of the nerves was achieved in $77.8 \%$ of patients in the taTME group and in only $33.3 \%$ of patients in the standard laparoscopic TME group. Besides better visualization, in the standard TME during anterior dissection of the mesorectum an excessive traction at the level of the seminal vesicles might injure the neurovascular bundle while during the taTME procedure this traction is avoided ${ }^{[12]}$. Nevertheless taTME has also several drawbacks. Prolonged dilatation of the anal canal with the trans-anal platform, might damage the sphincter muscles ${ }^{[13]}$ and a significantly longer distal resection margin has been described with taTME in several studies $^{[13,14]}$. As a result the anastomosis is potentially created more distally with a higher number of handsewn colo-anal anastomosis. This may impair anorectal function. Furthermore, a dissection in a more peripheral plane could produce inadvertent neural damage, particularly within the learning phase of the procedure $^{[15]}$. Finally an increased rate of urethral injury has been reported in the taTME international registry, which could lead to urinary incontinence and dysfunction ${ }^{[16]}$.

\section{FUNCTIONAL OUTCOME AFTER TME}

After rectal cancer surgery a substantial number of patients may report different complaints related to bowel, sexual, and urinary functions, social relationships and psychological aspects.

Functional bowel disturbance after rectal resection affects significant numbers of rectal cancer patients ${ }^{[17]}$. Many factors have been related to bowel dysfunction such as reduced capacity of the neorectum, damage to the bowel innervation and to the anal sphincter muscles and pudendal nerves, or loss of the rectoanal inhibitory reflex ${ }^{[18,19]}$. The level of anastomosis also plays a significant role while lower anastomosis, particularly colo-anal anastomosis and intersphincteric resections, can lead to a higher risk. In an attempt to improve postoperative bowel function, the construction of a side-to-end anastomosis, a J-pouch or a coloplasty has been performed with short term functional improvement but with minimal differences after a 2-year follow-up ${ }^{[20]}$. After rectal resection approximately $60 \%$ of patients experience some degree of fecal incontinence (FI). When evaluated by anorectal manometry, significant impairment of both internal and external sphincters, as well as reduced capacity of the neorectum have been demonstrated ${ }^{[21]}$.

In addition to fecal incontinence, one-third of patients complain other symptoms such as urgency, increased bowel frequency, fragmentation and soiling. These defecation disorders called "anterior resection syndrome" can seriously impact on quality of life ${ }^{[22]}$. Although the symptoms tend to improve over the first two years after surgery, a permanent impairment of anorectal function is often observed.

Genitourinary function impairment is mainly related to nerve injury during pelvic dissection. After laparoscopic or open TME the reported incidence of urinary dysfunction, including incontinence, retention and dysuria, ranges between $0 \%$ and $26 \%$. Sexual dysfunctions have been more intensively studied in men than in women; they involve erectile and ejaculatory problems, loss of desire, diminished sexual activity and anospermia, and ranges between $11 \%$ and $38 \%{ }^{[23-25]}$. In the Dutch trial, involving 1861 patients, urinary incontinence, 5 years postoperatively, was reported by $38 \%$ of patients, $72 \%$ of whom had normal urinary function before surgery. Additionally, general sexual dysfunctions 2 years after rectal cancer treatment were reported by $62 \%$ of women, and by $76 \%$ of men $^{[26]}$.

\section{QUALITY OF LIFE AFTER TME}

Quality of life (QoL) in rectal cancer patients is related to the presence and severity of the tumor, to sur- 
gical morbidity, to the effects of surgery on genitourinary and bowel function, and to adjuvant or neoadjuvant therapies. The relationship between postoperative functional disorders and QoL is not fully clarified and is not frequently reported in the literature; the impact of dysfunctions on well-being may vary according to patients' expectations and length of follow-up. The first studies investigating QoL after rectal cancer surgery were mainly focused on the effect of permanent stoma. Although there is a general consensus that QoL is worse after an abdominoperineal resection than after an anterior rectal resection, a recent Cochrane review failed to demonstrated a clear advantage of sphincter-saving operations over permanent colostomies $^{[27]}$. In a study by Vironen et al ${ }^{[28]}$ assessing surgery-related adverse effects on quality of life, major bowel dysfunction impaired social functioning, while incontinence and fecal urgency also affected mental health, and general health perception. Urinary dysfunctions worsened social functioning while, among sexual dysfunctions, only a complete loss of erection but no partial dysfunction, was associated with significantly worse physical and social functioning.

\section{INSTRUMENTS MEASURING FUNCTION AND QOL}

A number of scoring systems for the assessment of symptoms after rectal cancer surgery have been created in order to objectively describe the characteristics and severity of symptoms and to compare the outcomes of different conservative and surgical treatments or to compare results of published data.

For the evaluation of continence, information on frequency and quantity of loss is fundamental ${ }^{[29]}$, but the ability to defer defecation, the use of pads, the impact of symptoms on work activity or on lifestyle ${ }^{[30,31]}$ or the use of specific medication ${ }^{[32]}$ should be also taken into account.

For other bowel dysfunctions arising after rectal resection, a low anterior resection syndrome score (LARS score) has been created and has been recently internationally validated ${ }^{[22]}$; based on the results, three groups with no, minor and major LARS have been described. This scale is a reliable tool in clinical practice, also considering the high correlation between the LARS score and quality of life: significant differences were found between patients with no LARS and major LARS particularly in several subscales such as global health, social functioning and role functioning ${ }^{[33]}$.

Concerning the assessment of quality of life, several questionnaires have been expressly created for evaluating the health status of cancer patients ${ }^{[34]}$ or, more specifically, of colorectal cancer patients ${ }^{[35]}$. Postoperative QoL in cancer patients depends on many factors related to the tumor itself, to the treatments or to dysfunctions. These cancer specific questionnaires more accurately reflect the impact of all these factors on different aspects of health, since more generic questionnaires, or questionnaires for other benign anorectal conditions, might not be of sufficient sensitivity to detect differences.

A more detailed description of questionnaires employed in the assessment of functional impairment and QoL in rectal cancer patients is reported in the Supplementary Material.

\section{ANORECTAL, SEXUAL, URINARY, AND QUALITY OF LIFE OUTCOMES AFTER TATME}

At present, data on anorectal, sexual and urinary functions after taTME are scanty. There are few studies, usually involving a limited number of patients, and short follow-up. Moreover, as far as function is concerned, few comparative studies with standard TME and no randomized trial are available.

Four studies published between 2013 and 2015, reflecting the initial experience with this technique, were mainly focused on feasibility and short term surgical results, however they also tried to assess anorectal symptoms. All of them only evaluated fecal incontinence symptoms. Three employed the Wexner Incontinence score ${ }^{[36-38]}$, while Atallah et al ${ }^{[39]}$ examined 20 patients with a telephone survey 8 weeks after ileosto- 
my closure: most patients stated they had less than one accident per day, and one patient reported lifestylelimiting incontinence that did not improve 12 months post-resection. In three of the studies incontinence symptoms were only evaluated after surgery ${ }^{[36,37,39]}$. In one study 6 patients completed the Wexner incontinence score one week and 6 months after surgery ${ }^{[38]}$ : mean score only slightly deteriorated from 0 to 3 at 6 months after surgery and 4 months after stoma closure. A similar mean Wexner score value of 3.3 was reported by Borreca et al. ${ }^{[36]}$ with no patient complaining of urgency symptoms. A worse anorectal function was reported by Rouanet et al ${ }^{[37]}$ who studied 30 patients with advanced or recurrent low rectal tumor with complex anatomical (male gender, high BMI, fatty mesorectum), or tumor characteristics (bulky anterior tumor, narrow radial margin). The patients completed the Wexner Incontinence score 12 months after stoma closure and the median score was 11 . Only $40 \%$ of patients were fully continent, while 15\% and 35\% reported incontinence to liquids and gas respectively; additionally $25 \%$ of the patients complained stool fragmentation.

The first study focusing more on functional results was published in 2015 and involved 52 patients with low rectal cancer, who underwent colo-anal or intersphincteric resection; the patients were evaluated at least 12 months after surgery or after stoma closure with the Wexner incontinence score questionnaire; bladder and sexual function were also evaluated. Three patients (5.7\%) required a colostomy because of severe fecal incontinence after intersphincteric resection. For the remaining 49 patients without a stoma, the median Wexner score was 4 (range: 3-12), 13 patients (28\%) reported stool fragmentation and difficult evacuation. Five patients $(8.9 \%)$ developed postoperative urinary retention that resolved within 3 months. Deterioration of sexual function, in male patients, was reported by $22.2 \%$, decreased potency by 2 and impotence by 2 patients (11.2\%). The authors concluded that taTME does not negatively impacts on functional outcomes, however there was not a comparative group ${ }^{[40]}$.

Kneist $e t$ al. ${ }^{[41]}$ published in 2016 the first study with a comprehensive prospective assessment of urinary, sexual and intestinal function after taTME using validated instruments. The study involved 10 patients who underwent taTME with colo-anal or intersphincteric resection. Preoperative function was compared to functional outcomes at 3,6 and 9 months, after surgery or stoma closure. A unique and added value of this study was that pelvic autonomic nerve preservation was intraoperatively assessed electrophysiologically: an electromyography of the anal sphincter and a cystomanometry were performed during electric stimulations along the pelvic walls during mesorectal dissection. All patients completed validated questionnaires assessing: urinary function (IPSS score) $)^{[42]}$, Quality of Life (QoL Index) ${ }^{[43]}$, male sexual function (IIEF score) ${ }^{[44]}$; female sexual function $(\mathrm{FSFI})^{[45]}$; anorectal function, determined by the Wexner score ${ }^{[30]}$, and by the low anterior resection syndrome (LARS) $\operatorname{scor}^{[22]}$. In addition residual urine volume was evaluated. None of the patients developed pathological residual urine volumes after at least unilateral functional pelvic nerve-sparing. No significant difference in bladder function was noted nevertheless IIEF score was lower than preoperative values. Of note sexual function was already impaired in $60 \%$ of patients preoperatively. The median Wexner score deteriorated from 1 to 7 at 6 months $(P=0.029)$. Four patients had major LARS at 1 month but only one at 6 months, with $40 \%$ of patients categorized as having no LARS and 50\% minor LARS. A worse QoL due to fecal incontinence was found in 3 out of the 10 patients, 2 of whom had a partial intersphincteric resection, and 1 suffered tumor progression. The authors' conclusion was that taTME has the potential to preserve continence, sufficient bowel function, and urogenital function. Although the study examined in a rigorous and comprehensive way all the functional outcomes, the sample size is small and there are too many confounding factors to draw any definitive conclusion ${ }^{[41]}$.

The most recently published study involved 30 patients with low and medium rectal cancer ${ }^{[15]}$. The following questionnaires were completed by the patients 1 week before and 1 and 6 months after surgery: EuroQoL, (EORTC) QLQ-CR29 ${ }^{[46]}$, and QLQ-C30 ${ }^{[47]}$, LARS score. Preoperative LARS score ranged between 7.3 and 23.5, with the mean score being 15.4; a significative increase to 35.7 was recorded at 1 month, but after 6 months, it fell to 21.7 , with no significative difference with respect to preoperative value; $33 \%$ of patients 
Table 1. Studies evaluating function and QoL in taTME

\begin{tabular}{|c|c|c|c|c|c|}
\hline Studies & $\begin{array}{c}\text { No. of } \\
\text { patients }\end{array}$ & Tumor characteristics & Function & Instruments & Time of evaluation \\
\hline Rouanet et al. ${ }^{[37]}, 2013$ & 21 & $\begin{array}{l}\text { Advanced or recurrent cancer, } \\
\text { complex anatomy or tumor }\end{array}$ & $\mathrm{FI}$ & WS & $\begin{array}{l}12 \text { months after stoma } \\
\text { closure }\end{array}$ \\
\hline Atallah et al. ${ }^{[39]}, 2014$ & 20 & $\begin{array}{l}\text { Low, mid locally advanced or } \\
\text { distal rectal cancer + complex } \\
\text { anatomy }\end{array}$ & $\mathrm{FI}$ & telephone survey & $\begin{array}{l}8 \text { weeks after stoma } \\
\text { closure }\end{array}$ \\
\hline Elmore et al.. ${ }^{[38]}, 2015$ & 6 & Low, mid rectal cancer & $\mathrm{FI}$ & WS & $\begin{array}{l}\text { Pre-operation, } \\
6 \text { months post }\end{array}$ \\
\hline Kneist et al. ${ }^{[41]}, 2016$ & 10 & $\begin{array}{l}\text { Low rectal cancer, colo-anal } \\
\text { anastomosis or partial inter- } \\
\text { sphincteric resection }\end{array}$ & $\begin{array}{l}\text { Bowel, urinary, } \\
\text { sexual functions, } \\
\text { QoL }\end{array}$ & $\begin{array}{l}\text { IPSS, IIEF, FSFI, LARS, } \\
\text { RUV, WS, QoL index }\end{array}$ & $\begin{array}{l}\text { Pre-operation, } \\
3,6,9 \text { months post- } \\
\text { operation }\end{array}$ \\
\hline Koedam et al. ${ }^{[15]}, 2017$ & 30 & $\begin{array}{l}\text { Any rectal cancer, with primary } \\
\text { anastomosis }\end{array}$ & $\begin{array}{l}\text { Bowel, urinary, } \\
\text { sexual functions, } \\
\text { QoL }\end{array}$ & $\begin{array}{l}\text { EQ-5D, QLQ-C30 } \\
\text { QLQ-CR29, LARS }\end{array}$ & $\begin{array}{l}\text { Pre-operation, } \\
1,6 \text { months post-opera- } \\
\text { tion }\end{array}$ \\
\hline Borreca et al. ${ }^{[36]}, 2015$ & $18^{\star}$ & Any rectal cancer & $\mathrm{FI}$ & WS & Post operation \\
\hline Tuech et al. ${ }^{[40]}, 2015$ & 52 & $\begin{array}{l}\text { Low rectal cancer, colo-anal } \\
\text { anastomosis or intersphincteric } \\
\text { resection }\end{array}$ & $\begin{array}{l}\text { Bowel, urinary, } \\
\text { sexual (male) } \\
\text { function }\end{array}$ & WS, interview & Post operation \\
\hline
\end{tabular}

*Total number of patients, only patients who had their stoma closed were evaluated but the number is not reported. WS: Jorge-Wexner score; IPSS: international prostate symptom score; IIEF: international index of erectile function; FSFI: female sexual function index; LARS: low anterior resection syndrome score; FI: fecal incontinence; QoL: quality of life; taTME: transanal total mesorectal excision

had major LARS but no colostomies were required. Both the overall QoL and the colorectal cancer specific QoL score significatively decreased one month after surgery, but most outcomes returned to baseline after 6 months, except for social function and anal pain. Urinary symptoms, incontinence, increased frequency or dysuria, did not change significantly after taTME. Sexual function significantly worsened at 1 month postoperatively, but returned to the same level as before surgery at 6 months. The authors' conclusion was that taTME is associated with acceptable QoL and functional outcomes comparable with conventional laparoscopic TME. Table 1 summarizes the articles dealing with functional results in taTME.

\section{CONCLUSIONS}

Given the limitations of the existing studies larger studies have been advocated. Several studies exploring this novel surgical technique and the functional sequelae have been registered into clinicaltrial.gov, and some of them are already recruiting patients. Among them the COLOR III trial ${ }^{[48]}$, an international, multicentre, randomized trial, is expected to enrol more than 1000 patients in 4 years. In addition to clinical and oncological parameters, quality of life and functional outcomes will be assessed at 1, 3, 6, 12, 24 and 36 months after surgery by means of specific questionnaires.

In conclusion, published data concerning anorectal function, urinary and sexual function, and quality of life after taTME are still scarce and comparative data are lacking. Based on the few available studies, taTME does not seem to substantially impair functional and quality of life outcomes when compared to laparoscopic abdominal TME. However further studies are needed to confirm these results; the ongoing studies and particularly the COLOR III trial, will hopefully provide more firm updates for a more accurate assessment of this promising technique.

\section{DECLARATIONS}

\section{Author's contribution}

The author solely contributed to the article.

\section{Availability of data and materials}

Not applicable. 


\section{Financial support and sponsorship}

None.

\section{Conflicts of interest}

The author declares that there are no conflicts of interest.

\section{Ethical approval and consent to participate}

Not applicable.

\section{Consent for publication}

Not applicable.

\section{Copyright}

(C) The Author(s) 2018.

\section{REFERENCES}

1. Heald RJ, Husband EM, Ryall RD. The mesorectum in rectal cancer surgery-the clue to pelvic recurrence? Br J Surg 1982;69: 613-6.

2. Sylla P, Rattner DW, Delgado S, Lacy AM. NOTES transanal rectal cancer resection using transanal endoscopic microsurgery and laparoscopic assistance. Surg Endosc 2010;24:1205-10.

3. Fernández-Hevia M, Delgado S, Castells A, Tasende M, Momblan D, Díaz del Gobbo G, DeLacy B, Balust J, Lacy AM. Transanal total mesorectal excision in rectal cancer: short term outcomes in comparison with laparoscopic surgery. Ann Surg 2015;261:221-7.

4. Muratore A, Mellano A, Marsanic P, De Simone M. Transanal total mesorectal excision (taTME) for cancer located in the lower rectum: short and mid-term results. Eur J Surg Oncol 2015;41:478-83.

5. Ito M, Sugito M, Kobayashi A, Nishizawa Y, Tsunoda Y, Saito N. Relationship between multiple numbers of stapler firings during rectal division and anastomotic leakage after laparoscopic rectal resection. Int J Colorectal Dis 2008;23:703-7.

6. Penna M, Knol JJ, Tuynman JB, Tekkis PP, Mortensen NJ, Hompes R. Four anastomotic techniques following transanal total mesorectal excision (TaTME). Tech Coloproctol 2016;20:185-91.

7. Arroyave MC, DeLacy FB, Lacy AM. Transanal total mesorectal excision (TaTME) for rectal cancer: Step by step description of the surgical technique for a two-teams approach. Eur J Surg Oncol 2017;43:502-5.

8. Perdawood SK, Al Khefagie GA. Transanal versus laparoscopic total mesorectal excision for rectal cancer: initial experience from Denmark. Colorectal Dis 2016;18:51-8.

9. Kanso F, Maggiori L, Debove C, Chau A, Ferron M, Panis Y. Perineal or abdominal approach first during intersphincteric resection for low rectal cancer: which is the best strategy? Dis Colon Rectum 2015;58:637-44.

10. Denost Q, Adam JP, Rullier A, Buscail E, Laurent C, Rullier E. Perineal transanal approach: a new standard for laparoscopic sphinctersaving resection in low rectal cancer, a randomized trial. Ann Surg 2014;260:993-9.

11. Chouillard E, Regnier A, Vitte RL, Bonnet BV, Greco V, Chahine E, Daher R, Biagini J. Transanal NOTES total mesorectal excision (TME) in patients with rectal cancer: is anatomy better preserved? Tech Coloproctol 2016;20:537-44.

12. Moszkowicz D, Alsaid B, Bessede T, Penna C, Nordlinger B, Benoît G, Peschaud F. Where does pelvic nerve injury occur during rectal surgery for cancer? Colorect Dis 2011;13:1326-34.

13. Hompes R, Arnold S, Warusavitarne J. Towards the safe introduction of transanal total mesorectal excision: the role of a clinical registry. Colorectal Dis 2014;16:498-501.

14. Chen CC, Lai YL, Jiang JK, Chu CH, Huang IP, Chen WS, Cheng AY, Yang SH. Transanal total mesorectal excision versus laparoscopic surgery for rectal cancer receiving neoadjuvant chemoradiation: a matched case-control study. Ann Surg Oncol 2016;23:1169-76.

15. Koedam TWA, van Ramshorst GH, Deijen CL, Elfrink AKE, Meijerink WJ, Bonjer HJ, Sietses C, Tuynman JB. Transanal total mesorectal excision (TaTME) for rectal cancer: effects on patient-reported quality of life and functional outcome. Tech Coloproctol 2017;21:25-33.

16. Penna M, Hompes R, Arnold S, Wynn G, Austin R, Warusavitarne J, Moran B, Hanna GB, Mortensen NJ, Tekkis PP; TaTME Registry Collaborative. Transanal total mesorectal excision: international registry results of the first 720 cases. Ann Surg 2017;266:111-7.

17. Bryant CL, Lunniss PJ, Knowles CH, Thaha MA, Chan CL. Anterior resection syndrome. Lancet Oncol 2012;13:e403-8.

18. Pucciani F. A review on functional results of sphincter-saving surgery for rectal cancer: the anteriorresection syndrome. Updates Surg 2013;65:257-63

19. O'Riordain MG, Molloy RG, Gillen P, Horgan A, Kirwan WO. Rectoanal inhibitory reflex following low stapled anterior resection of the rectum. Dis Colon Rectum 1992;35:874-8.

20. Ziv Y, Zbar A, Bar-Shavit Y, Igov I. Low anterior resection syndrome (LARS): cause and effect and reconstructive considerations. Tech Coloproctol 2013;17:151-62.

21. De Nardi P, Testoni SGG, Corsetti M, Andreoletti H, Giollo P, Passaretti S, Testoni PA. Manometric evaluation of anorectal function in patients treated with neoadjuvant chemoradiotherapy and total mesorectal excision for rectal cancer. Dig Liver Dis 2017;49:91-7.

22. Emmertsen KJ, Laurberg S. Low anterior resection syndrome score: development and validation of a symptom-based scoring system for bowel dysfunction after low anterior resection for rectal cancer. Ann Surg 2012;255:922-8. 
23. Maurer CA. Urinary and sexual function after total mesorectal excision. Recent Results Cancer Res 2005;165:196-204.

24. Pocard M, Zinzindohoue F, Haab F, Caplin S, Parc R, Tiret E. A prospective study of sexual and urinary function before and after total mesorectal excision with autonomic nerve preservation for rectal cancer. Surgery 2002;131:368-72.

25. Quah HM, Jayne DG, Eu KW, Seow-Choen F. Bladder and sexual dysfunction following laparoscopically assisted and conventional open mesorectal resection for cancer. Br J Surg 2002;89:1551-6.

26. Lange MM, van de Velde CJ. Urinary and sexual dysfunction after rectal cancer treatment. Nat Rev Urol 2011;8:51-7.

27. Pachler J, wille-Jorgensen P. Quality of life after rectal resection for cancer, with or without permanent stoma. Cochrane Database Syst Rev 2005;2:CD004323.

28. Vironen JH, Kairaluoma M, Aalto AM, Kellokumpu IH. Impact of functional results on quality of life after rectal cancer surgery. Dis Colon Rectum 2006;49:568-78.

29. Pescatori M, Anastasio G, Bottini C. New grading system and scoring for anal incontinence. Evaluation of 335 patients. Dis Colon Rectum 1992;35:482-7.

30. Jorge JM, Wexner SD. Etiology and management of fecal incontinence. Dis Colon Rectum 1993;36:77-97.

31. American Medical Systems. Fecal incontinence scoring system. Minnetonka: American Medical Systems; 1996.

32. Vaizey CJ1, Carapeti E, Cahill JA, Kamm MA. Prospective comparison of faecal incontinence grading systems. Gut 1999;44:77-80.

33. Emmertsen KJ, Laurberg S; Rectal Cancer Function Study Group. Impact of bowel dysfunction on quality of life after sphincter-preserving resection for rectal cancer. Br J Surg 2013;100:1377-87.

34. Aaronson NK, Ahmedzai S, Bergman B, Bullinger M, Cull A, Duez NJ, Filiberti A, Flechtner H, Fleishman SB, de Haes JCJM, Kaasa S, Klee MC, Osoba D, Razavi D, Rofe PB, Schraub S, Sneeuw KCA, Sullivan M, Takeda F. The European Organization for Research and Treatment of Cancer QLQ-C30: a quality-of-life instrument for use in international clinical trials in oncology. J Natl Cancer Inst 1993;85:365-76.

35. Whistance RN, Conroy T, Chie W, Costantini A, Sezer O, Koller M, Johnson CD, Pilkington SA, Arraras J, Ben-Josef E, Pullyblank AM, Fayers P, Blazeby JM; European Organization for the Research and Treatment of Cancer Quality of Life Group. Clinical and psychometric validation of the EORTC QLQ-CR29 questionnaire module to assess health-related quality of life in patients with colorectal cancer. Eur J Cancer 2009;45:3017-26.

36. Borreca D, Bona A, Bellomo MP, Borasi A, De Paolis P. The new approach to the rectal cancer: 'down-to-up' double endolaparoscopic pelvic access. Preliminary evaluation of outcomes. Updates Surg 2015;67:293-9.

37. Rouanet P, Mourregot A, Azar, Carrere S, Gutowski M, Quenet F, Saint-Aubert B, Colombo P. Transanal endoscopic proctectomy: an innovative procedure for difficult resection of rectal tumors in men with narrow pelvis. Dis Colon Rectum 2013;56:408-15.

38. Elmore U, Fumagalli Romario U, Vignali A, Sosa MF, Angiolini MR, Rosati R. Laparoscopic anterior resection with transanal total mesorectal excision for rectal cancer: preliminary experience and impact on postoperative bowel function. J Laparopendosc Adv Surg Tech A 2015;25:364-9.

39. Atallah S, Martin-Perez B, Albert M, deBeche-Adams T, Nassif G, Hunter L, Larach S. Transanal minimally invasive surgery for total mesorectal excision (TAMIS-TME): results and experience with the first 20 patients undergoing curative-intent rectal cancer surgery at a single institution. Tech Coloproctol 2014;18:473-80.

40. Tuech JJ, Karoui M, Lelong B, De Chaisemartin C, Bridoux V, Manceau G, Delpero JR, Hanoun L, Michot F. A step toward NOTES total mesorectal excision for rectal cancer: endoscopic transanal proctectomy. Ann Surg 2015;261:228-33.

41. Kneist W, Wachter N, Paschold M, Kauff D, Rink A, Lang H. Midterm functional results of taTME with neuromapping for low rectal cancer. Tech Coloproctol 2016;20:41-9.

42. Prestil J, Kane CJ, Shinohara K. Neoplasm of the prostate gland. Smith's General Urology. 7th ed. 2008. p. 351.

43. Barry MJ, Adolfsson J, Batista-Miranda JE. Committee 6: measuring the symptoms and health impact of benign prostatic hyperplasia and its treatments. In: Denis L, Griffiths K, Khoury S, editors. Proceedings of the fourth international consultation on benign prostatic hyperplasia. Plymouth: Health Publication Ltd; 1998. p. 265-321.

44. Rosen RC, Riley A, Wagner G, Osterloh IH, Kirkpatrick J, Mishra A. The international index of erectile function (IIEF): a multidimensional scale for assessment of erectile dysfunction. Urology 1997;4:822-30.

45. Rosen R, Brown C, Heiman J, Leiblum S, Meston C, Shabsigh R, Ferguson D, D’Agostino R Jr. The female sexual function index (FSFI): a multidimensional self-report instrumentfor the assessment of female sexual function. J Sex Marital Ther 2000;26:191-208.

46. Whistance RN, Conroy T, Chie W, Costantini A, Sezer O, Koller M, Johnson CD, Pilkington SA, Arraras J, Ben-Josef E, Pullyblank AM, Fayers P, Blazeby JM; European Organisation for the Research and Treatment of Cancer Quality of Life Group. Clinical and psychometric validation of the EORTC QLQ-CR29 questionnaire module to assess health related quality of life in patients with colorectal cancer. Eur J Cancer 2009;45:3017-26.

47. Fayers P, Aaronson NK, Bjordal K, Groenvold M, Curran D, Bottomley A. EORTC QLQ-C30 Scoring Manual. 3rd ed. Brussels: European Organisation for Research and Treatment of Cancer; 2001.

48. Deijen CL, Velthuis S, Tsai A, Mavroveli S, de Lange-de Klerk ES, Sietses C, Tuynman JB, Lacy AM, Hanna GB, Bonjer HJ. COLOR III: a multicentre randomised clinical trial comparing transanal TME versus laparoscopic TME for mid and low rectal cancer. Surg En$\operatorname{dosc} 2016 ; 30: 3210-5$. 